\title{
Correction to: Response of solute transport model parameters to the combination of multiple design parameters and their quantitative expression with hydraulic indicators of FWS-constructed wetlands
}

\author{
Changqiang Guo ${ }^{1,2} \cdot$ Yuanlai Cui $^{1} \cdot$ Yufeng Luo $^{1}$ \\ Published online: 17 August 2020 \\ (C) Springer-Verlag GmbH Germany, part of Springer Nature 2020
}

Correction to: Environmental Science and Pollution Research https://doi.org/10.1007/s11356-020-10250-Z

The correct Fig. 6 is presented in this paper.

The original article has been corrected.

The online version of the original article can be found at https://doi.org/ $10.1007 / \mathrm{s} 11356-020-10250-\mathrm{Z}$

\footnotetext{
Yuanlai Cui

YLCui@whu.edu.cn

1 State Key Laboratory of Water Resource and Hydropower Engineering Science, Wuhan University, Wuhan 430072, China

2 College of Biosystems Engineering and Food Science, Zhejiang University, Hangzhou 310058, China
} 

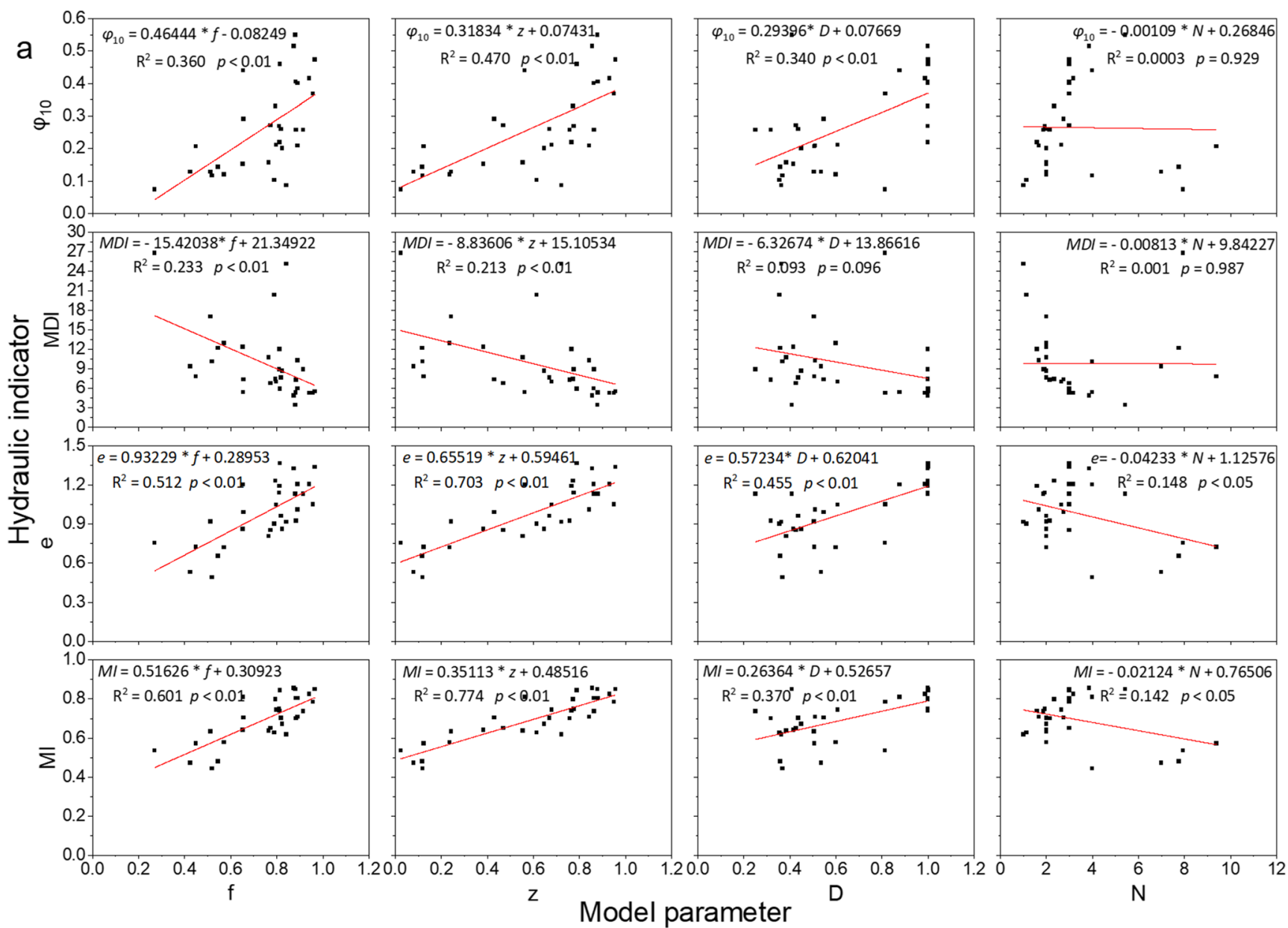

Fig. 6 a Correlation between the PFD + CSTR model parameters and hydraulic indicators combining the August and July 2017 data and b variation of hydraulic indicators and model parameters for the 2016 and

2017 tests. The missing values in the diagram (9th sequence in 2017.07 and 12th, 14th in 2016) were neglected because their coefficients of determination R2 from simulation fitting were below 0.6 

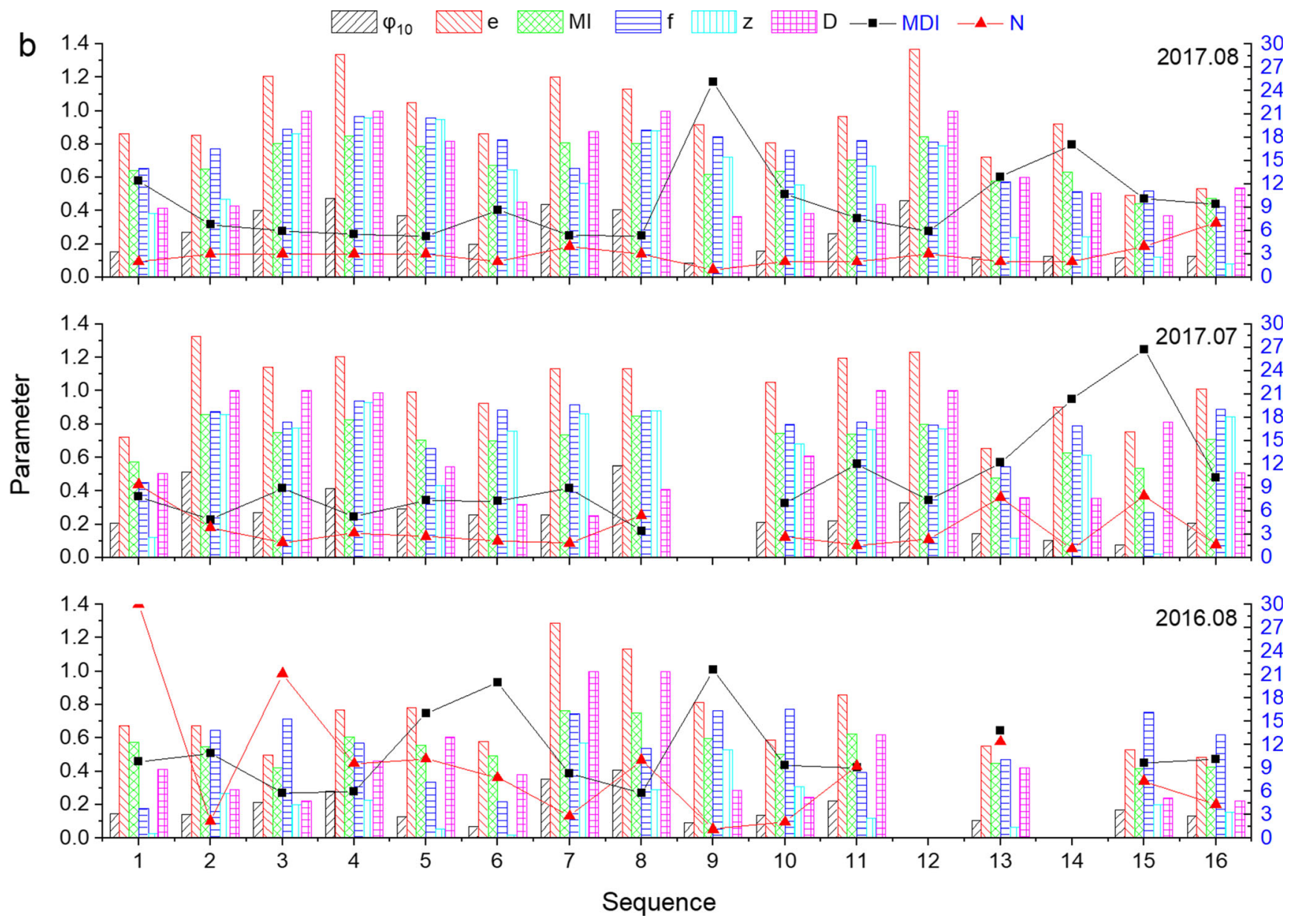

Fig. 6 (continued)

Publisher's note Springer Nature remains neutral with regard to jurisdictional claims in published maps and institutional affiliations. 